Hidefumi Obara MD, Daisuke Sugiyama MD, Nobuhiro Maekawa MD, Susumu Hamatani MD, Osamu Tanaka MD, Riichiro Chuma MD, Sanji Kitamura MD, Seizo Iwai MD

\title{
Plasma cortisol levels in paediatric anaesthesia
}

possible to measure small samples and has stimu-

We measured plasma cortisol levels during surgery in seven neonates within ten days after birth and in 14 infanis ranging in age from three months to 11 months. The 14 infants were divided into two groups; Group I included eight infanis in whom general anaesthesia was maintained with oxygen, nitrous oxide and a muscle relaxant, Group II, six infants in whom general anaesthesia was muintained with oxygen, nitrous oxide, halothane and a muscle relaxant. In the neonates, the changes in mean plasma cortisol levels during anaesthesia were not statistically significant. In both Group I and Group II infants, the mean cortisol levels gradually rose during anaesthesia, but the initial rise in plasma cortisol levels was suppressed in the patients who received halothane.

Key words

ANAESTHESIA: paediatric; HORMONES: corticosteroids.

It is well recognized that an increased secretion of corticosteroids occurs in adults under conditions of stress, including surgical stress. ${ }^{1.2}$ The magnitude of this response is proportional to the severity of the surgical injury. ${ }^{3}$ Clarke et al. showed a significant rise in plasma cortisol levels during major surgery and a small rise during minor surgery. ${ }^{3}$ In contrast, the responsiveness of the neonatal adrenal cortex in the face of surgical stimuli and other types of stress has not been well established.

In recent years the development of hormone assay (Radioimmunoassay method) has made it

From The Department of Angesthesia, Kobe University School of Medicine, Kusunoki-cho 7, Chuo-ku, Kobe, Japan 650 .

Address correspondence to: Hidefumi Obara MD, Department of Anaesthesia, Kobe University School of Medicine, Kusunoki-cho 7, Chuo-ku, Kobe, Japan 650. lated studies on the effects of anaesthetics and surgical stimuli on the endocrine system in neonates and infants. The present study was designed to evaluate adrenal cortical function during surgery, as measured by plasma cortisol, in neonates and in infants.

\section{Methods}

Plasma cortisol levels were determined in seven neonates within ten days after birth and in 14 infants ranging in age from three months to 11 months. Informed consent was obtained at the preoperative visit from the parents. The 14 infants were divided as follows: (Group I) eight infants in whom general anaesthesia was maintained with oxygen, nitrous oxide and a muscle relaxant; (Group II) six infants in whom general anaesthesia was maintained with oxygen, nitrous oxide, halothane and a muscle relaxant. The details of surgery and anaesthesia are shown in Table $\mathbf{I}$. The seven neonates underwent abdominal surgery with the exception of one thoracotomy for a tracheo-esophageal fistula. All of the infants in Group $I$ and in Group II underwent abdominal surgery. One infant in Group II underwent both thoracotomy and gastrostomy for a tracheo-esophageal fistula.

All of the patients were given $0.02 \mathrm{mg} \mathrm{kg}^{-1}$ of atropine intramuscularly 30 minutes before anaesthesia. The neonates were intubated after $0.1 \mathrm{mg}$. $\mathrm{kg}^{-1}$ of pancuronium bromide had been given intravenously. Anaesthesia in the infants was induced with nitrous oxide $4 \mathrm{l} / \mathrm{min}$, oxygen $2 \mathrm{l} / \mathrm{min}$, and halothane in gradually increasing concentrations up to two per cent. Immediately after onset of sleep, all patients were intubated, after $0.1 \mathrm{mg} \cdot \mathrm{kg}^{-1}$ of pancuronium bromide was given intravenously and the halothane was discontinued in Group I patients. Anaesthesia was maintained with 60 per cent nitrous oxide, 40 per cent oxygen and pancuronium in the neonates and Group I infants, and 
TABLE I Details of patienıs

\begin{tabular}{|c|c|c|c|}
\hline & \multirow[b]{2}{*}{ Neonates $(n=7)$} & \multicolumn{2}{|l|}{ Infants } \\
\hline & & Group $I(n=8)$ & Group $I(\{n=6)$ \\
\hline Age (days) & $3.3=0.7$ & & \\
\hline (month) & & $6.9 \pm 1.2$ & $7.8 \pm 1.1$ \\
\hline Sex (female) & 4 & 1 & 1 \\
\hline (male) & 3 & 7 & 5 \\
\hline Gestational age (weeks) & $39.3 \pm 0.6$ & & \\
\hline Weight (g) & $2656 \pm 246$ & $6402 \pm 687$ & $7275 \pm 1204$ \\
\hline Duration of anaesthesia (hours) & $3.49 \pm 0.38$ & $4.98 \pm 0.81$ & $5.76 \pm 0.44$ \\
\hline Duration of operation (hours) & $2.89 \pm 0.42$ & $3.57 \pm 0.78$ & $4.54 \pm 0.46$ \\
\hline
\end{tabular}

Mean \pm S.E

Neonate: within 10 days after birth.

Infant: ranging in age from three months to 11 months.

with 60 per cent nitrous oxide, 40 per cent oxygen, 0.5 to 1 per cent halothane and pancuronium in Group II infants.

Blood loss was estimated by weighing sponges and was replaced with a similar volume of blood. During anaesthesia, all of the patients received an intravenous solution at a rate of $10-15 \mathrm{ml} \cdot \mathrm{kg}^{-1} \cdot \mathrm{hr}$, consisting of $\mathrm{Na} 45 \mathrm{mEq}, \mathrm{Cl} 35 \mathrm{mEq}$, and $2.5 \mathrm{per}$ cent glucose in a $500 \mathrm{ml}$ solution. Arterial blood samples for determining cortisol levels were obtained from a femoral artery just after the induction of general anaesthesia; from an indwelling radial artery 15 and 90 minutes after incision and immediately after the end of surgery. The radial artery catheter was routinely used for measuring the arterial blood pressure during anaesthesia. Blood samples were immediately centrifuged and frozen for storage until the cortisol levels were determined by the immunoassay method. We used a Cortisol Radioimmunoassay Kit supplied by Daiichi Radioisotope Institute.

Statistical analysis was performed using analysis of variance, the paired Student's $t$ test and the unpaired Student's $t$ test to compare data within individual groups and between two subgroups in infants. ${ }^{4}$

\section{Results}

The mean cortisol levels are shown in the Figure and Table II and the mean plasma cortisol level of fresh blood, which replaced lost blood, was $13.8 \pm$ $1.8 \mu \mathrm{g} / 100 \mathrm{ml}$ (mean $=\mathrm{S} . \mathrm{E}$.) in the neonates and $16.2 \pm 1.0 \mu \mathrm{g} / 100 \mathrm{ml}$ in the infants.
In the neonates, the mean cortisol levels gradually rose until 90 minutes after the surgical incision and fell by the end of surgery. These changes in the mean plasma cortisol levels from the induction levels were not statistically significant.

There was no significant difference in the plasma cortisol levels between Group I and Group II at the induction of anaesthesia. In both Group I and Group II the plasma cortisol levels rose gradually, but the levels in Group II remained lower than those in Group I. The rise in the plasma cortisol levels in Group I was statistically significant 15 minutes and 90 minutes after incision and at the end of surgery. In contrast, the rise in the plasma cortisol levels in Group II was not significant 15 minutes and 90 minutes after incision, but was significant at the end of surgery, as compared to the induction level.

\section{Discussion}

After birth the adrenal cortex in neonates undergoes marked enzymatic and anatomic changes. The large foetal cortex degenerates during the second week of life though the small adult cortex gradually increases in thickness. ${ }^{5}$ During pregnancy the foetal adrenal cortex can synthesize cortisol through two pathways: mainly from placental progesterone and, to a lesser degree, from acetate because the foetal cortex is deficient in 3-hydroxysteroid-dehydrogenase activity. ${ }^{5}$ After birth, the adult cortex predominantly supplies all cortisol for the period of adaptation to extrauterine life.

The responsiveness of the neonatal adrenal cortex in the face of stress is controversial, and there 


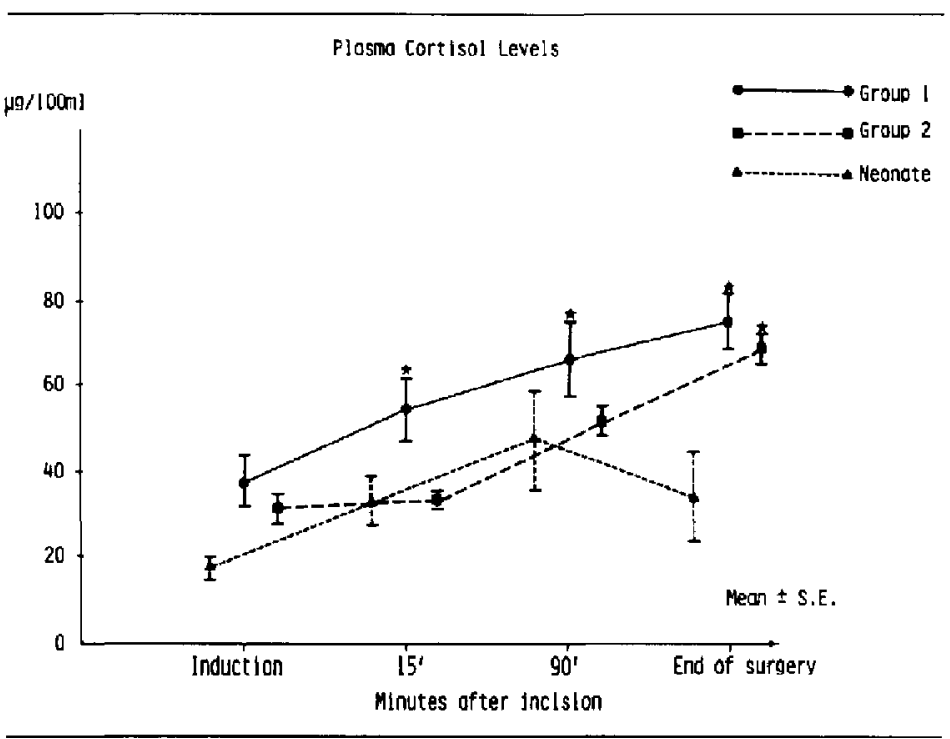

FICURE The mean plasma cortisol levels in neonates, Group l infants and Group II infants (Mean \pm S.E. , $\mu \mathrm{g} / 100 \mathrm{ml}$ plasma). See text for details.

* Significant increase from the induction level $(p<0.05)$.

TABLE II Plasma cortisol levels

\begin{tabular}{lllll}
\hline & & \multicolumn{2}{l}{$\mu g / 100 \mathrm{ml}$ piasma } \\
\cline { 3 - 4 } & & \multicolumn{2}{l}{ Minutes affer incision } & \\
\cline { 3 - 5 } Group & Induction & $15^{\prime}$ & $90^{\prime}$ & End of surgery \\
\hline Neonate $(\mathrm{n}=7)$ & $17.9 \pm 2.6$ & $33.1 \pm 7.0$ & $48.2 \pm 11.5$ & $33.7 \pm 10.7$ \\
Group $1(\mathrm{n}=8)$ & $37.3 \pm 6.2$ & $54.9 \pm 7.1^{*}$ & $66.8 \pm 8.3^{*}$ & $75.2 \pm 6.3^{*}$ \\
& & $\dagger$ & $\dagger$ & $\dagger$ \\
Group II $(\mathrm{n}=6)$ & $31.5 \pm 4.5$ & $33.7 \pm 1.7$ & $51.7 \pm 3.5$ & $59.1 \pm 3.6^{*}$ \\
\hline
\end{tabular}

Mean \pm S.E.

- Significant increase from the induction level $(p<0.05)$

†Significant difference between two infant subgroups $(p<0.05)$.

are some reports on the adrenal response in neonates subjected to surgery. Colle and Ulstrom ${ }^{6}$ measured the urinary excretion of corticosteroids in five neonates operated on during the first four days of life. No rise in corticosteroid excretion was observed following surgery, but the baseline excretion of corticosteroids was high. In contrast, Miura et al. ${ }^{7}$ reported a significant rise of plasma cortisol levels and urinary 17-hydroxysteroid excretion in three neonates less than one week of age subjected to stress during abdominal surgery. In our current study, the plasma cortisol levels of the neonates showed a gradual but statistically insignificant rise until 90 minutes after surgery and a fall at the end of surgery, Recent studies have shown that neonates are able to respond to physical stress with an increase in plasma cortisol. Baden et al. ${ }^{8}$ reported that 44 premature infants with respiratory distress 
syndrome had higher levels of cortisol than nonstressed premature infants, and a significant correlation was found with the five-minute Apgar score. Reynolds ${ }^{9}$ reported similar results in premature infants with fatal hyaline membrane disease, when compared to non-fatal and benign respiratory distress syndrome. Kenny et al. ${ }^{10}$ showed that newborn infants less than five days of age secreted more cortisol per body surface area than older infants, children and adults. Gutai et al ${ }^{11}$ found that newborn infants were able to respond to the intramuscular administration of $\mathrm{ACTH}$, which resulted in a significant rise in cortisol levels.

Several explanations for the lack of adrenal cortical response to surgical stimuli in the present study of neonates may be proposed. Perhaps the general anaesthesia induced with oxygen, nitrous oxide, and a muscle relaxant suppressed the adrenal response to surgical stress and therefore the plasma cortisol level was unable to rise in neonates during surgery. Another possible explanation is that the hypothalamic-pituitary system or adrenal cortex in reonates less than one week old was unable to respond to surgical stimuli because of hypofunction.

In contrast, Group I infants who received general anaesthetics similar to those of the neonates showed a significant rise in plasma cortisol levels after surgical incision, and these levels continued to rise until the end of surgery. Group II infants also showed a gradual rise of plasma cortisol levels after the surgical incision, but the change was not statistically significant. In Group II infants only the plasma cortisol levels at the end of surgery were significantly increased. We suggest that the differences in response to surgical stress between Group I and Group $I$ are due to differences in the anaesthetic procedures. Our present study shows that halothane anaesthesia diminishes the response to surgical stimuli in infants, more than does general anaesthesia induced with oxygen, nitrous oxide and a muscle relaxant without halothane.

\section{References}

1 Johnston IDA. The metabolic and endocrine response to injury. Br J Anaesth 1973; 45: 252-68.

2 Oyama $T$. Endocrine responses to anaesthetic agents. Вr J Anaesth 1973; 45: 276-81.
3 Clarke RSJ, Jahnston $H$, Sheridan $B$. The influence of anaesthesia and surgery on plasma cortisol, insulin and free fatty acids. Br J Anaesth 1970; 42: $295-9$.

4 Wallenstein $S$, Zucker $C L$, Fleiss $J L$. Some statistical methods useful in circulation research. Circ Res 1980; 47: 1-9.

5 Villee $D B$. Development of endocrinc function in the human placenta and fetus. N Engl J Med I969; 281: 473-84

6 Colle $E$, Ulstrom $R A$. Urinary excretion of corticosteroids in infants: The response to surgery and corticotrophin (ACTH). Am J Dis Child 1959; 98: 574-5.

7 Miura J, Fujimoto S, Kin Y. Plasma cortisol levels during pediatric surgery. JSPS 1978; 14: 133.

8 Baden $M$, Bauer $C R$, Colle $E$, Klein $G$, Papageargiou A, Stern $L$. Plasma corticosteroids in infants with the respiratory distress syndrome. Pediatrics 1973; 52: 782-7.

9 Reynolds $J W$. Serum total corticoid and cortisol levels in premature infants with respiratory distress syndrome. Pediatrics 1973; 51: 884-90.

10 Kenny $F M$, Preeyasombar $C$, Migeon $C J$. Cortisol production rate. II. Normal infants, children and adults. Pediatrics 1966; 37: 34-42.

11 Gutai J, George R, Koeff S, Bacon GE. Adrenal response to physical stress and the effect of adrenocorticotropic hormone in newborn infants. J Pediatr 1972; 81: 719-25.

Résumé

Les niveaur plasmatiques de cartisol ont été mesurés chez sept nouveau-nés à moins de dix jours d'age et chez 14 enfants de trois à 11 mois. Ces enfants ont été rêpartis en deux groupes: le groupe I - huit enfants sous anesthésie gènérale à l'oxygène-protoxyde et un myorésolutif et le groupe II - six enfants chez qui l'anesshésie générale a été entretenue avec de l'oxygène-protoxyde d'azote, de l' halothane et un myo-résolutif.

Chez les nouveau-nés, des changements de la concentration plasmatique moyenne du cortisol n'étaient pas statistiquement significatifs. Chez les patients des groupes $I$ et $I I$, les niveaux moyens de corrisol plasmatique ont augmenté graduellement durant l'anesthésie mais chez ceux qui ont reçu de l' halothane, l'augmentation initiale du cortisol plasmatique a éré supprimée. 